\title{
A PLANIFICAÇÃO DA EDUCAÇÃO DOS ANOS 30 A 60: PIONEIRISMO, REFORMAS, SUBMISSÃO E TECNOCRACIA
}

\author{
Alberto Damasceno \\ Universidade Federal do Pará - UFPA
}

\section{RESUMO}

Esse artigo aborda o processo de planificação educacional no país, dentro do período que vai da década de 30 até a década de 60 quando o processo de organização da educação atravessava momentos de avanços e recuos, dependendo da conjuntura política dominante. Enquanto as décadas de 30 e 40 representaram uma fase de pioneirismo e implementação de reformas estruturantes, mais à frente, como resultado das profundas mudanças históricas ocorridas nas décadas de 50 e 60, o planejamento educacional vivenciou experiências de submissão ao desenvolvimento econômico, à tecnocracia e ao autoritarismo.

Palavras-chave: Política Educacional; Planejamento da Educação; Reforma Educacional.

\section{EDUCATION PLANNING FROM THE THIRTIES TO THE SIXTIES: PIONEERING, REFORMS, SUBMISSION AND TECHNOCRACY}

\begin{abstract}
This article discusses the process of educational planning in the country within the period from the $30 \mathrm{~s}$ to the $60 \mathrm{~s}$ when the organization process of education goes through moments of advances and retreats, depending on the prevailing political situation. While the decades of 30 and 40 represented a phase of pioneering and implementation of structural reforms, further, as a result of profound historical changes that occurred in the 50s and 60s, educational planning experienced submission to economic development, technocracy and authoritarianism.
\end{abstract}

Keywords: Educational Policy; Educational Planning; Educational Reform.

O físico e o químico não terão necessidade de saber o que está e se passa além da janela do seu laboratório. Mas o educador, como o sociólogo, tem necessidade de uma cultura múltipla e bem diversa; as alturas e as profundidades da vida humana e da vida social não devem estender-se além do seu raio visual; ele deve ter o conhecimento dos homens e da sociedade em cada uma de suas fases, para perceber, além do aparente e do efêmero, "o jogo poderoso das grandes leis que dominam a evolução social", e a posição que tem a escola, e a função que representa, na diversidade e pluralidade das forças sociais que cooperam na obra da civilização (Manifesto dos Pioneiros).

As reformas educacionais desencadeadas por simpatizantes do ideário da Escola Nova ${ }^{1}$ durante a década de 20 enraizaram suas bases conceituais e metodológicas no Estado brasileiro a ponto de dar suporte às iniciativas tomadas por Getúlio Vargas durante o governo provisório entre os anos de 1930 a 1934. 
Entretanto, isso não foi suficiente para que, no que tange ao planejamento educacional, os processos se desencadeassem de modo independente e autônomo. Uma das conclusões do simpósio sobre planejamento da educação realizado por ocasião da XXIV Reunião Anual da Sociedade Brasileira para o Progresso da Ciência (SBPC) no início da década de 70 ratificava a ideia de que

Como sucede muitas vezes, a urgência das providências de ação tem relegado a plano secundário qualquer preocupação com vistas à definição clara de conceitos e à formação sistemática de pessoal qualificado para o trato de complexo instrumental técnico envolvido na atividade de planejamento. São poucos os cursos formais que visam, direta ou indiretamente, à formação de quadros de planejadores da educação, e raras as atividades informais que propiciem a troca de ideias e de experiências nesse campo.

Característica dessa situação é a preponderância de economistas e de órgãos de marcado caráter econômico nos trabalhos de planejamento da educação: sem dúvidas, são eles os que dispõem do saber do manejo das técnicas e das ferramentas para a elaboração de planos, mas pode-se temer que seu interesse e habilidades em relação ao fenômeno educativo possam ser insuficientes para permitir-lhes evitar, no ato de planejar, muitos de seus vieses econômicos, que podem resultar em ações menos adequadas, quando se trata de planejamento da educação (SIMPÓSIO, 1972, p.8).

Para Moreira (1972), esse foi um problema reconhecido por técnicos da UNESCO quando afirmavam, àquela época, que a técnica da planificação era nova e sofria, desde seu início da falta de pessoal qualificado. Além disso, o estabelecimento de metas a serem cumpridas no âmbito do planejamento educacional por meio legal, parece nunca ter despertado o interesse das elites dirigentes do país. Por seu turno, Mendes (2000) considera que a institucionalização do planejamento educacional no Brasil tem dois marcos decisivos, quais sejam:

a Lei de Diretrizes e Bases da Educação Nacional (Lei $\mathrm{n}^{\circ} 4.024$, de 20/12/61) e a Reforma Administrativa (Decreto-lei n 200, de 25/2/67). À margem da primeira, e do sistema de planejamento que ela consagrou, desenvolveu-se, por via administrativa, e por força de impulsos diversos, um sistema paralelo que veio a ser finalmente homologado e consolidado pela segunda (MENDES: 2000, p.23).

Em seu estudo, Mendes (2000) também faz referência às tendências pedagógicoeducacionais que se enfrentavam na arena do planejamento educacional brasileiro; de um lado ele alinhava os educadores liberais, e de outro, os técnicos do Ministério do Planejamento. Dizia ele:

Entretanto, os princípios constitucionais que servem de fundamento último a ambos os sistemas de planejamento - na medida em que expressam a mesma filosofia política e educacional - têm permanecido invariáveis. Esses princípios se referem, basicamente, aos fins da educação, ao direito de todos à educação, à obrigação do Estado de ministrar o ensino nos três graus, à liberdade da iniciativa privada, amparada financeira e tecnicamente pelos poderes públicos, e à subsidiaridade da ação federal em relação aos sistemas estaduais de 
educação (MENDES: 2000, p.23).

Em 14 de novembro de 1930, por meio do Decreto 19.402, foi criado o Ministério da Educação e da Saúde Pública que, a partir de então, com Francisco Campos à frente, promoveu uma reforma constituída, basicamente, por sete decretos ${ }^{2}$. Dentre eles estava o de número 19.850, de 11 de abril de 1931, que criou o Conselho Nacional de Educação cujas atribuições, segundo Cury, teve como uma de suas consequências, a apresentação, pelo conselheiro João Simplício Alves de Carvalho (na sessão de 27 de junho de 1931) de uma proposta de criação de "uma ou mais comissões para o preparo e a redação de um plano nacional de educação" (CURY, 2009, p. 13). Naquela ocasião Alves de Carvalho propunha que:

o Conselho Nacional de Educação, tendo presente os objetivos patrióticos de sua instituição e fazendo uso das atribuições fundamentais, que lhe confere o decreto n. 19.850, de 11 de abril de 1931, designe uma ou mais comissões para o preparo e a redação de um plano nacional de educação, o qual deve ser aplicado e executado em um período de tempo, que nele será fixado.

Esse plano procurará satisfazer as exigências da atualidade brasileira, tomando em consideração as condições sociais do mundo, e assegurará, pela sua estrutura e pela sua aplicação, o fortalecimento da unidade brasileira, o revigoramento racial de sua gente e o despertar dos valores indispensáveis ao seu engrandecimento econômico; e, depois de estudado e aprovado pelo Conselho Nacional de Educação, será submetido ao exame do Governo da República e à consideração dos Governos dos Estados (CARVALHO, João Simplício Alves apud CURY, 2009, 15).

Entretanto, a maioria dos estudiosos que se dedicam a contar a história do planejamento da educação no Brasil afirmam o Manifesto dos Pioneiros como a primeira grande inciativa no sentido de destacar o papel essencial e imprescindível de um plano para a educação nacional, denominado àquela época de "Plano de Reconstrução Educacional".

O Manifesto dos Pioneiros da Educação Nova lançado em 1932, no contexto da preparação da Assembléia Nacional Constituinte de 1933, com o sugestivo título "A reconstrução educacional no Brasil: ao povo e ao Governo", pode ser considerado o marco inicial da preocupação com um projeto nacional de educação, com visão sistêmica, de totalidade. (BORDIGNON, 2011, p. 3).

Além disso, para Saviani (1999), o Manifesto diagnostica o estado da educação pública no Brasil e enuncia as diretrizes fundamentais e culmina com a formulação de um plano de reconstrução educacional. É a partir do documento redigido pelos intelectuais da Educação Nova que é defendida, pioneiramente, uma estrutura mais moderna e adequada que acolhesse harmônica e integralmente os diferentes níveis de ensino articulados ao desenvolvimento da pessoa, observando a integralidade da organização e dos métodos, propugnando a superação da educação estática em favor de um conceito dinâmico da mesma e enaltecendo a potencialidade criativa do aluno.

A estrutura do plano educacional corresponde, na hierarquia de suas instituições escolares (escola infantil ou pré-primária; primária; secundária e superior ou universitária) aos quatro grandes períodos que 
apresenta o desenvolvimento natural do ser humano. É uma reforma integral da organização e dos métodos de toda a educação nacional, dentro do mesmo espírito que substitui o conceito estático do ensino por um conceito dinâmico, fazendo um apelo, dos jardins de infância à Universidade, não à receptividade mas à atividade criadora do aluno. (MANIFESTO, 1932, sp).

Os Pioneiros já reconheciam no nível secundário a dualidade prejudicial existente entre a escola da burguesia e dos setores populares, fruto dos interesses de classe que permeavam sua organização e, para além da dimensão ideológica, preocupavam-se com a natureza e características dos conteúdos a serem desenvolvidos nesse nível, de modo que o consideravam o principal problema nas reformas educacionais.

Mas, montada, na sua estrutura tradicional, para a classe média (burguesia), enquanto a escola primária servia à classe popular, como se tivesse uma finalidade em si mesma, a escola secundária ou do $3^{\circ}$ grau não forma apenas o reduto dos interesses de classe, que criaram e mantêm o dualismo dos sistemas escolares. É ainda nesse campo educativo que se levanta a controvérsia sobre o sentido de cultura geral e se põe o problema relativo à escolha do momento em que a matéria do ensino deve diversificar-se em ramos iniciais de especialização. Não admira, por isto, que a escola secundária seja, nas reformas escolares, o ponto nevrálgico da questão (MANIFESTO, 1932, sp).

Além dessas análises, os pioneiros também eram conhecedores das dificuldades enfrentadas para consignar um plano organizativo para a educação brasileira.

[...] se depois de 43 anos de regime republicano, se der um balanço ao estado atual da educação pública, no Brasil, se verificará que, dissociadas sempre as reformas econômicas e educacionais, que era indispensável entrelaçar e encadear, dirigindo-as no mesmo sentido, todos os nossos esforços, sem unidade de plano e sem espírito de continuidade, não lograram ainda criar um sistema de organização escolar, à altura das necessidades modernas e das necessidades do país (Idem, 1932, sp).

Por tudo isso, é inegável a influência que o Manifesto exerceu sobre a Constituição de 1934, a ponto de a mesma estabelecer em seu artigo 150, como competência da União, "fixar o plano nacional de educação, compreensivo do ensino de todos os graus e ramos, comuns e especializados; e coordenar e fiscalizar a sua execução, em todo o território do país" (BRASIL, 1934). Importante destacar que a Carta Magna de 34 também previu no artigo 152 a constituição de um Conselho Nacional de Educação organizado na forma da lei com vistas a "elaborar o plano nacional de educação para ser aprovado pelo Poder Legislativo e sugerir ao Governo as medidas que julgar necessárias para a melhor solução dos problemas educativos bem como a distribuição adequada dos fundos especiais." (Idem, 1934). Aos estados e ao Distrito Federal, no contexto de sua legislação própria e em seu âmbito de competências também coube estabelecer Conselhos de Educação com funções similares às do Conselho Nacional.

Cumprindo as determinações legais, o Conselho se dedicou à tarefa e depois de 50 reuniões plenárias "com participação do Ministro nas 14 primeiras e nas duas últimas" (BORDIGNON: 2011, 6), entregou em maio de 1937 ao então ministro da educação, 
Gustavo Capanema, uma proposta de Plano de Educação Nacional que se caracterizava em um código da educação nacional e como

um conjunto de princípios e normas adotados por esta lei para servirem de base à organização e funcionamento das instituições educativas, escolares e extra-escolares, mantidas no território nacional pelos poderes públicos ou por particulares (ver BORDIGNON, 2011, 6).

No mesmo mês, Capanema entregou ao presidente o ante projeto de Lei a ser encaminhado à Câmara dos Deputados, ali foi criada uma "Comissão do Plano Nacional de Educação", que elaborou um relatório para iniciar o debate na Comissão de Educação e Cultura. Entretanto, em novembro de 1937, Getúlio articula e executa um Golpe de Estado e institui a Ditadura do Estado Novo, dissolvendo as casas legislativas em todos os níveis. Desta feita, o nascente plano nacional de educação não passou de uma proposta natimorta.

No que se refere ao financiamento da educação, desde a Colônia até meados da terceira década do século $\mathrm{XX}$, não se tem notícia de uma legislação específica que garantisse aplicação de recurso público no ensino, pois essa iniciativa era deixada à mercê da chamada "vontade política" dos governantes, seja cedendo a reivindicações das classes trabalhadoras, seja por motivos que julgasse convenientes.

Com a Constituição Federal de 1934, teve início, no Brasil, a vinculação constitucional de recursos para a manutenção e o desenvolvimento do ensino. No Artigo 156 dessa Carta Magna ficou disposto, pela primeira vez, que "a União e os Municípios aplicarão nunca menos de dez por cento, e os Estados e o Distrito Federal nunca menos de vinte por cento da renda resultante dos impostos na manutenção e no desenvolvimento dos sistemas educativos." Essa vinculação estabelecida na Constituição de 1934 quase não se concretizou porque, com a implantação do Estado Novo, a Constituição de 1937 a ignorou (LOUREIRO, 2010, sp).

Como vimos, o regime de exceção gerou uma nova Constituição - agora outorgada - que determinou, em seu artigo 15 (inciso IX), que à União competia privativamente "fixar as bases e determinar os quadros da educação nacional, traçando as diretrizes a que deve obedecer à formação física, intelectual e moral da infância e da juventude" (BRASIL: 1937). Para Bordignon (2011)

No Estado Novo as propostas de organização da educação assumiram um caráter moralista, expresso, segundo proposta do Ministro Capanema, num Código da Educação Nacional, a estabelecer os princípios fundamentais, os valores aos quais a educação deve servir, que deveriam reger toda a educação nacional (p. 7).

Para que esse código pudesse ser elaborado, o Ministro Capanema propôs ao presidente Vargas em uma exposição de motivos datada de 27 de janeiro de 1941 a realização de uma conferência prevista na Lei 378, de 13 de janeiro de 1937, que segundo o ministro,

[...] deu organização nova ao Ministério da Educação e Saude [sic], instituiu a Conferência Nacional de Educação e a Conferência Nacional de Saude [sic], como órgãos destinados a promover o permanente entendimento deste Ministério com os governos estaduais no terreno da 
administração dos negócios de sua competência. Motivos de força maior retardaram a convocação dessas conferências nacionais. Por outro lado, o andamento dos serviços não as tornou imprecindíveis [sic] (BRASIL, 1941?).

A proposta foi aceita e, por meio do Decreto 6.788, de 30 de janeiro de 1941 o presidente convocou as conferências para o "decurso do $1^{\circ}$ semestre daquele mesmo ano". Constavam como assuntos principais de seus trabalhos: a) organização, difusão e elevação da qualidade do ensino primário e normal e do ensino profissional; b) organização em todo o país da Juventude Brasileira (BRASIL, 1941).

Por meio da Portaria Ministerial $\mathrm{n}^{\circ} 73$ de abril de 1941 a Conferência foi prevista originalmente para 22 de junho do mesmo ano; em maio, o Decreto 719 adiou-a para a segunda quinzena de setembro e o Decreto 8.090 de outubro, adiou-a novamente para 3 de novembro daquele ano. Entretanto, como nos informa Bordignon (2011),

sobrevindo questões políticas nacionais e internacionais - declaração de guerra à Itália e Alemanha em 1942 e organização da Força Expedicionária Brasileira (FEB) em 1943 - a conferência não produziu os efeitos previstos - o Código Nacional de Educação não chegou a ser elaborado - , nem outras conferências foram realizadas (p. 7).

Com a vitória dos países aliados na Segunda Guerra Mundial, dentre outros fatores, Getúlio perde força e renuncia, propiciando a retomada da democracia a partir de 1945, o que foi determinante para que, segundo Bordignon, "os ideais dos Pioneiros renascessem das cinzas". Isso se deu, sobretudo, porque,

No período do Estado Novo os educadores organizados na ABE [Associação Brasileira de Educação] não abandonaram seu sonho de um projeto nacional de educação. Em junho de 1945, no clima da redemocratização, a ABE realizou seu IX Congresso Brasileiro de Educação tendo como objetivo o estudo e planejamento da educação nacional em todos os graus, segundo diretrizes e em bases democráticas (BORDIGNON, 2011, p.8).

Para retomar o estado de direito a Constituição de 1946 baseou-se em princípios liberais e democráticos, sendo o instrumento legal para a reorganização nacional, agora sob novas bases, e a introdução de inovações importantes, inclusive para a educação, que passa a ser compreendida como direito de todos e ser garantida em todos os níveis pelo Estado, juntamente com a iniciativa privada. Outro aspecto importante foi a garantia da gratuidade do ensino primário oficial, assegurada para todos. Todavia, nos níveis seguintes, só os que provassem insuficiência de recursos poderiam estudar sem dispêndio.

Quanto à questão do financiamento, outra vitória importante foi conquistada. A partir das lutas em defesa da democracia, a sociedade civil organizada garantiu a reintrodução, no texto constitucional, da vinculação de recursos para a educação. No artigo 169 , ficou estabelecido que "anualmente, a União aplicará nunca menos de $10 \%$, e os Estados, o Distrito Federal e os Municípios nunca menos de $20 \%$ da renda resultante dos impostos na manutenção e no desenvolvimento do ensino".

Outro aspecto importante é o fato de a Constituição de 1946 estabelecer, como competência da União, no seu artigo $5^{\circ}$ (inciso XV, alínea d), "legislar sobre diretrizes e bases da educação nacional". Segundo Bordignon a Carta Magna corrige 
o equívoco de 1934 que dava ao plano um caráter de lei de diretrizes e bases. No capítulo da educação, manteve a organização dos sistemas de ensino, e vinculou a renda resultante dos impostos na manutenção e desenvolvimento do ensino em $10 \%$ da União e $20 \%$ dos Estados, Distrito Federal e Municípios (art. 169) e estabeleceu o princípio da cooperação da União com auxílio pecuniário para o desenvolvimento dos sistemas de ensino estaduais e do Distrito Federal, o qual, em relação ao ensino primário, provirá do respectivo Fundo Nacional (BORDIGNON: 2011, p.8).

Em que pesem todos os esforços de Gustavo Capanema, as consequências de suas iniciativas não chegaram a ser tão significativas. Mesmo após as medidas tomadas no sentido de estruturar o arcabouço da educação nacional, seja por meio do Código da Educação Nacional ou por via da elaboração de um Plano Nacional de Educação, sua única conquista resultou na edição das Leis Orgânicas do Ensino de 1942, cujo conjunto ficou conhecido como "Reforma Capanema" (ver SAVIANI, 1999, p.126-127). Após o fím do Estado Novo, em 1946, os Decretos se deram sob a liderança do Ministro Raul Leitão da Cunha ${ }^{3}$.

Com o advento das décadas de 50 e 60, a planificação educacional passou a ser subordinada aos ditames do desenvolvimento e reprodução do capital sob a égide da tecnocracia ${ }^{4}$. Além desse aspecto, tivemos também o confronto entre duas visões de planejamento, antagônicas e inconciliáveis:

No período compreendido entre 1946 e 1964 observa-se uma tensão entre duas visões de Plano de Educação que, de certo modo, expressa a contradição entre as forças que se aglutinaram sob a bandeira do nacionalismo desenvolvimentista que atribuíam ao Estado a tarefa de planejar o desenvolvimento do país libertando-o da dependência externa, e aquelas que defendiam a iniciativa privada se contrapondo à ingerência do Estado na economia e àquilo que taxavam de monopólio estatal do ensino. Ambas essas tendências repercutiram no debate que se travou por ocasião da discussão no Congresso Nacional do projeto da nossa primeira Lei de Diretrizes e Bases da Educação Nacional (SAVIANI, 1999, p.127).

Esse processo se intensifica a partir da implantação do Regime Militar por meio de um golpe apoiado pela CIA e por parte do empresariado nacional em abril de 1964 .

Sobre o planejamento como instrumento de intervenção estatal, base do desenvolvimento nacional, Neves argumenta que ele surge

de forma embrionária, no cenário brasileiro, somente a partir da década de 40, assumindo, paulatinamente, o seu papel de instrumento organizador do processo de acumulação, à medida em que se foram consolidando as bases do projeto de industrialização no país (NEVES, 1984, p.56).

Um exemplo recorrente do conceito acima descrito é o Plano de Metas de Juscelino Kubistchek. Entretanto, Júnior (1995) nos alerta para o fato de, apesar de vários autores o apontarem como uma experiência de planejamento econômico bem-sucedida no Brasil, ele 
se tratava mais de um conjunto de metas de desenvolvimento a serem atingidas, incidindo nos setores de energia, transportes, alimentação, indústrias de base e educação, do que propriamente de um plano articulado que contemplasse, de forma sistemática, todas as facetas do desenvolvimento nacional (JÚNIOR, 1995, p. 6).

Ainda para esse autor "uma formulação mais global só veio a ser realizada com a confecção do Plano Trienal de Desenvolvimento Econômico e Social, elaborado em 1962 por uma equipe coordenada pelo economista Celso Furtado e que propunha soluções estruturais para o desenvolvimento nacional, com preocupações nitidamente sociais. (JÚNIOR: 1995, p. 6). Bordignon corrobora essa tese destacando que a educação constituía a meta 30 do Plano de Metas e era situada como "demanda derivada" $(2011$, p.8), cujo objetivo era intensificar a formação de pessoal técnico e orientar a educação para o desenvolvimento. Em outras palavras, a educação, naquele planejamento, estava irremediavelmente submetida ao preceito do desenvolvimento econômico.

Apesar de a criação de uma lei de diretrizes para a educação estar prevista desde 1946, quando foi promulgada a Constituição daquele ano, somente 15 anos depois tivemos sua aprovação pelo Poder Legislativo. Seguindo o disposto na Carta Magna, que atribuía à União a competência para legislar sobre as diretrizes e bases da educação nacional (art. $5^{\circ}$, inciso XV, alínea d), o governo federal, por meio do Ministro Clemente Mariani, encaminhou ao Congresso Nacional o projeto de Lei de Diretrizes e Bases para a Educação.

Em 20 de dezembro de 1961 seria aprovada a Lei $\mathrm{n}^{\circ}$ 4.024, conhecida como primeira Lei de Diretrizes e Bases da Educação Nacional (LDB), que estabeleceu que os recursos destinados à manutenção e desenvolvimento do ensino pelo art. 169 da Constituição de 1946, fossem distribuídos em Fundos para cada setor, atribuindo ao Conselho Federal de Educação a competência de elaborar o plano de aplicação de cada fundo, conforme o artigo 92 (BORDIGNON, 2011, p.9).

De acordo com Saviani, nas discussões por ocasião da elaboração da LDB prevaleceu a tese que defendia a liberdade de ensino e o direito da família de escolher o tipo de educação que desejava para seus filhos, partindo da premissa de que uma ação "planificada" do Estado poderia promover o indesejável "totalitarismo".

Em decorrência dessa orientação, a idéia de Plano de Educação na nossa primeira LDB ficou reduzida a instrumento de distribuição de recursos para os diferentes níveis de ensino. De fato, pretendia-se que o Plano garantisse o acesso das escolas particulares, em especial as católicas, aos recursos públicos destinados à educação (SAVIANI: 1999, p.127).

No que tange ao financiamento, promulgada a Lei 4.024, de 1961, o percentual da União, de $10 \%$, estabelecido pela Constituição, foi elevado para $12 \%$ de aplicação na manutenção e no desenvolvimento do ensino, preferencialmente o público.

Além disso, a mesma estabelecia em seu artigo 92, parágrafo $1^{\circ}$ que, com nove décimos dos recursos federais destinados à educação, seriam constituídos o Fundo Nacional do Ensino Primário, o Fundo Nacional do Ensino Médio e o Fundo Nacional do Ensino Superior; posteriormente, no parágrafo $2^{\circ}$, a norma determinava que o Conselho Federal de Educação deveria elaborar, para execução em prazo determinado, o Plano de Educação referente a cada Fundo. Tal formulação foi objeto de crítica pelo fato de que a 
ideia de planejamento presente na referida LDB não era aquela presente nos debates iniciais em torno da necessidade de um plano global para a educação nacional.

A ideia de plano de Educação, tal como aparece na LDBEN, não tem nenhuma relação com o que se entendia por planejamento educacional na época de sua elaboração final, seja a idéia de um "plano de Educação" defendida pelos educadores liberais, seja a visão de "planejamento integral da Educação" em íntima relação com o planejamento econômico e social, dominante em organismos internacionais de Educação e já presente no Brasil no final da década de 1950 (HORTA, 1982, p.18).

Sob influência dessas contradições o Conselho Federal de Educação - cujo presidente era Anísio Teixeira - começou a tarefa de elaborar a minuta de Plano, considerando que

a educação constitui serviço comum e solidário das três órbitas administrativas do país, sendo a ação do Governo Federal fundamentalmente supletiva e devendo, portanto, os planos a serem elaborados ter em vista os serviços dos Estados e dos Municípios no campo da educação e ensino. Deste modo, os planos deverão visar, acima de tudo, a oferecer a oportunidade e indicar as formas pela qual os três governos possam coordenar os seus esforços para a consecução dos objetivos previstos na Constituição e na Lei de Diretrizes e Bases. (TEIXEIRA, 1962 apud BORDIGNON: 2011, p.10).

Cumprida a missão, o Conselho entregou o projeto de Plano em 21 de setembro de 1962 ao Ministro da Educação Darcy Ribeiro, para que fosse encaminhado à apreciação pelo Poder Legislativo. Essa proposta fazia referência

aos Fundos Nacionais de Ensino Primário, Médio e Superior, que definia metas quantitativas e qualitativas para cada nível de ensino para o período de 1963-1970, normas reguladoras de aplicação de cada fundo e plano de aplicação dos recursos para o ano de 1963 . O período de validade de 8 (oito) anos para o Plano levava em conta metas educacionais definidas pelo governo (COPLAN e COPLED) ${ }^{5}$ e compromissos internacionais assumidos pelo Brasil nos encontros de Lima, Punta del Leste e Santiago do Chile (BORDIGNON, 2011,p.10).

Dado o Golpe em 64, seu líder e primeiro presidente militar, General Castelo Branco, encontra em vigência o Plano Decenal de Desenvolvimento Econômico e Social, elaborado pelo governo de João Goulart. Referido plano, que desenhava metas para o período de 1967 a 1976, não chegou a ser executado. Sobre ele Horta argumenta que, "principalmente a partir do Plano Decenal de Desenvolvimento Econômico e Social, o CFE [Conselho Federal de Educação] começou a perder, na prática, a prerrogativa de elaborar o Plano Nacional de Educação, que, sem base legal, lhe fora atribuída" (1982, 218). É a partir desse momento que o protagonismo dos "pedagogos" vai sendo substituído pelo protagonismo dos "tecnocratas" do Ministério do Planejamento no que tange ao planejamento educacional.

Quanto aos recursos financeiros para a educação, Loureiro nos informa que também, a partir desse momento, 
foi elaborada a Constituição de 1967, que vai revelar o descompromisso do Estado com a educação pública. A Constituição de 1967 suprime os percentuais a serem aplicados em educação pela União, Estados e Distrito Federal e mantém a obrigatoriedade da aplicação somente para os Municípios.

A Lei 5.692/71, conhecida como reforma de ensino de $1^{\circ}$ e $2^{\circ}$ graus, seguindo as determinações constitucionais, omitiu os percentuais a serem aplicados pela União e Estados em educação (LOUREIRO, 2010, sp).

\section{CONSIDERAÇÕES FINAIS}

As décadas de 30 e 40 representaram, no campo das políticas educacionais e do planejamento da educação uma fase de pioneirismo e implementação de reformas estruturantes. Isso porque o período foi bastante influenciado pelas reformas realizadas na década anterior ${ }^{6}$. Um marco inicial foi a criação do Ministério da Educação e Saúde Pública em 1930, sob a gestão de Francisco Campos, que consignou a primeira grande reforma educacional da República brasileira. Houve, também, a realização de uma Conferência de Educação, além da promulgação de uma Constituição democrática e a promoção de um inquérito nacional para subsidiar um plano nacional que nunca chegou a virar lei. O encerramento do período se dá com a promulgação das Leis Orgânicas sob a liderança de Gustavo Capanema, entre 1942 e 1943, e sob a tutela de Raul Leitão da Cunha em 1946.

Entretanto, como vimos no decorrer do período, entre as iniciativas e medidas adotadas não houve previsão de processos de formação de pessoal para as atividades de planejamento, o que propiciou a influência de economistas e a preponderância de órgãos de natureza econômica na área do planejamento da educação, fato que pode ter determinado deformações indesejadas, em razão de um economicismo exacerbado na definição das grandes linhas da educação nacional. Em consequência, após as profundas mudanças históricas ocorridas nas décadas de 50 e 60 o planejamento educacional vivenciou experiências de submissão ao desenvolvimento econômico e à tecnocracia. $\mathrm{O}$ início do período se deu com o Plano de Metas de Juscelino Kubistchek, caracterizado pela forte vinculação do planejamento da educação ao planejamento macroeconômico, foi marcado pela edição de um novo manifesto de educadores e a promulgação da primeira lei de diretrizes e bases da educação nacional. Tivemos, mais uma vez, um plano que nunca chegou a ser executado e foi concluído com a reforma universitária em 1968, sob um regime de exceção.

Desde a década de trinta, os educadores têm enfrentado dificuldades para a elaboração e execução de um plano educacional adequado para a nação brasileira, sobretudo em razão de divergências quanto a sua natureza e fins. Desse modo, é forçoso reconhecer que, em nosso país, a concepção e execução do planejamento educacional comumente estiveram subordinadas a interesses outros, que não os da educação propriamente dita, até porque a inexistência de uma política educacional como eixo orientador das ações comprometia a percepção do planejamento como ferramenta de efetivação de suas diretrizes e metas.

Sendo assim, podemos afirmar que a realização da concepção de planejamento como tarefa institucional comprometida com a emancipação escolar e educacional das classes populares sempre enfrentou obstáculos significativos, seja em razão de deficiências estruturais e de insuficiência de pessoal qualificado, até o predomínio de uma visão utilitária e economicista da política educacional. 


\section{REFERÊNCIAS}

BITTAR, Marisa ; JR, Amarilio Ferreira. Educação e Ideologia Tecnocrática na Ditadura Militar. Caderno CEDES. Campinas, vol.28, p. 333-335, set/dez, 2008.

BORDIGNON, Genuíno et alli. O planejamento educacional no Brasil. Brasília. Fórum Nacional de Educação. Junho/2011.

BRASIL. $1^{a}$ Conferência Nacional de Educação e $1^{\text {a }}$ Conferência Nacional de Saúde. Ministério da Educação e Saúde. Serviço de Documentação, Folheto n 5. [1941?].

. Constituição dos Estados Unidos do Brasil. 1934.

. Constituição Federal de 1937.

CURY, Carlos Jamil. O direito à educação: um campo de atuação do gestor educacional na escola. SD. Disponível em: http://escoladegestores.mec.gov.br/site/8biblioteca/pdf/jamilcury.pdf. Acesso em 03/02/2015.

CURY, Carlos Jamil. Por um Plano Nacional de Educação: nacional, federativo, democrático e efetivo. In: RBPAE, v.25, n.1, p. 13-30, jan./abr. 2009.

HORTA, José Silvério Baia. Liberalismo, tecnocracia e planejamento educacional no Brasil: uma contribuição à história da educação brasileira no período 1930-1970. São Paulo: Cortez / Autores Associados. 1982.

IVASHITA, Simone Burioli e VIEIRA, Renata de Almeida. Os antecedentes do manifesto dos pioneiros da educação nova (1932). Disponível em: http://www.histedbr.fe.unicamp.br/acer_histedbr/seminario/seminario8/_files/GuEVnTfr.p df. Acesso em: 29/01/2015.

JÚNIOR, Heitor Frúgoli. Estrutura do planejamento e planejamento educacional no Brasil. In: Revista de Administração Pública. São Paulo Fundação Getúlio Vargas. V. 29, N 1, 1995.

LOUREIRO. Walderês Nunes. O financiamento da educação no Brasil: contextualização. In: Anais do Simpósio de estudos e pesquisas da FE/UFG, 2010. Disponível

em: https://anaisdosimposio.fe.ufg.br/up/248/o/3_LOUREIRO_Walderes_Nunes.pdf. Acesso em: 16/01/2015.

MANIFESTO dos Pioneiros. A reconstrução educacional no Brasil: Ao povo e ao governo. 1932.

Disponível

em:

http://www.histedbr.fe.unicamp.br/revista/edicoes/22e/doc1_22e.pdf. Acesso em: $16 / 12 / 2014$.

NEVES, Lúcia Wanderley et ali. Estado e planejamento educacional no Brasil: a formação do planejador. In: Cadernos de pesquisa. São Paulo: Fundação Carlos Chagas. N 51, 1984.

PARDIM, Carlos Souza ; SOUZA, Luzia Aparecida. O movimento da Escola Nova no Brasil na década de 30. Universidade Federal do Mato Grosso do Sul, s/d. Disponível em: http://www.uems.br/eventos/semana2012/arquivos/49_2012-09-28_15-35-43.pdf. Acesso em: $15 / 02 / 15$.

SAVIANI, Dermeval. Sistemas de ensino e planos de educação: o âmbito dos municípios. In: Revista Educação \& Sociedade, ano XX, nº 69, Dezembro/99. 


\begin{abstract}
Notas
1. "A Escola Nova foi um movimento educacional que, por meio de propostas pedagógicas, procurou modernizar o ensino trazendo para a escola as novas descobertas, nos ramos das várias ciências. Segundo Lamego (1996), a Escola Nova propunha quatro pontos básicos: 1) A "revisão crítica" dos meios tradicionais do ensino, nos quais a individualidade não era fator de preocupação. 2) Inclusão de fatores históricos e culturais da vida social na formação educacional. 3) A utilização dos novos conhecimentos da biologia e da psicologia para que o educador estabeleça os estágios de maturação do indivíduo na infância, assim como o desenvolvimento de sua capacidade individual. 4) A transferência da responsabilidade da ação educadora da família e da Igreja para a Escola, como forma de amenizar as diferenças sociais e culturais existentes entre os diversos grupos e, juntamente com isso, a responsabilização do Estado pela educação do indivíduo. Este movimento educacional tinha como representantes no Brasil, Fernando de Azevedo, Anísio Teixeira, Afrânio Peixoto, Lourenço Filho, entre outros. Estes intelectuais, inspirados pelos ideais da Escola Nova, procuraram implantar um novo modelo educacional no país. Foi na Revolução de 1930, que pôs fim à Primeira República no Brasil derrubando uma política voltada às grandes oligarquias rurais, que estes Renovadores perceberam a oportunidade de se implantar tal projeto que viria modernizar a atual situação do ensino no Brasil. Porém, conforme aponta Lamego (1996), algumas das ideias defendidas por este Movimento contrariavam o interesse de dois grupos de grande influência no Brasil: a Igreja Católica, e o grupo liderado pelo ministro da educação Francisco Campos.” (PARDIM e SOUZA, s/d).
\end{abstract}

2. Decreto ${ }^{\circ} 19.850$, de 11 de abril de 1931 (que criou o Conselho Nacional de Educação); Decreto ${ }^{\circ}$ 19.851, da mesma data (que dispôs sobre a organização do ensino superior no Brasil e adotou o regime universitário); Decreto ${ }^{\circ} 19.852$, também da mesma data (que dispôs sobre a organização da Universidade do Rio de Janeiro); Decreto $\mathrm{n}^{\circ}$ 19.890, de 18 de abril de 1931 (que dispôs sobre a organização do ensino secundário); Decreto $\mathrm{n}^{\circ}$ 19.941, de 30 de abril de 1931 (que instituiu o ensino religioso como matéria facultativa nas escolas públicas do País); Decreto ${ }^{\circ} 20.158$, de 30 de junho de 1931 (que organizou o ensino comercial e regulamentou a profissão de contador); Decreto $\mathrm{n}^{\circ} 21.241$, de 14 de abril de 1932 (que consolidou as disposições sobre a organização do ensino secundário).

3. Decreto-lei n. 4.073, de 30 de janeiro de 1942, que organizou o ensino industrial; Decreto-lei n. 4.048, de 22 de janeiro de 1942, que instituiu o SENAI; Decreto-lei n. 4.244 de 9 de abril de 1942, que organizou o ensino secundário em dois ciclos: o ginasial, com quatro anos, e o colegial, com três anos; Decreto-lei $\mathrm{n}$. 6.141, de 28 de dezembro de 1943, que reformou o ensino comercial; Decreto-lei n. 8.529, de 02 de janeiro de 1946, que organizou o ensino primário em nível nacional; Decreto-lei 8.530, de 02 de janeiro de 1946, que organizou o ensino normal; Decretos-lei n 8.621 e 8.622, de 10 de janeiro de 1946, que criaram o SENAC e; Decreto-lei n. 9.613 de 20 de agosto de 1946, que organizou o ensino agrícola.

4. A tecnocracia, concebida como o governo da técnica, instaurada com intensidade no estado brasileiro a partir do golpe militar de 64 "estava diretamente relacionada à supressão das liberdades democráticas e à célere modernização das relações capitalistas de produção, isto é, sem democracia era impossível criticar, fiscalizar e controlar as decisões econômicas e sociais adotadas pelos tecnocratas, em relação às políticas implementadas pelos governos que se sucederam entre 1964 e 1985. A consequiência daí derivada foi a institucionalização do tecnicismo como ideologia oficial de Estado. Assim, a difusão generalizada dessa ideologia ganhou materialidade, particularmente, após a edição do Ato Institucional $\mathrm{n}^{\circ} 5$ (AI 5), em dezembro de 1968. A partir de então, a ditadura militar, com base na censura imposta aos meios de comunicação de massa, produziu um conjunto articulado de idéias, valores, opiniões e crenças, segundo o qual a tecnocracia era a melhor forma de se governar a sociedade brasileira. (BITTAR e JR, AMARILIO, $2008,342)$

5. A COPLAN (Comissão Nacional de Planejamento) foi criada em 1961 por Jânio Quadros para construir o sistema de planejamento e a COPLED (Comissão de Planejamento da Educação) era instância do Ministério da Educação e Cultura, instituída em 1962. Ambas atuaram na Coordenação Setorial da Educação, com o objetivo de:" a) reunir, coordenar ou realizar os estudos e levantamentos necessários ao planejamento plurianual da Educação no País; b) coordenar e harmonizar, em planos gerais e setoriais, os programas e projetos de Educação elaborados por órgãos públicos e entidades privadas, em matéria de Educação; c) assistir os estados e municípios na elaboração dos respectivos planejamentos, oferecendo-lhes a necessária assistência técnica". (HORTA: 1982, 57). 
6. O ideal reformador teve início com um movimento educacional gestado por volta da década de 1920 , quando iniciaram as primeiras reformas educacionais em diferentes estados brasileiros. A primeira reforma foi realizada em São Paulo, no ano de 1920 por Sampaio Dória; em 1922 a reforma foi empreendida no Ceará por Lourenço Filho e no Distrito Federal em 1927 realizada por Fernando de Azevedo. Segundo Romanelli (1978) houve ainda as reformas nos estados de Pernambuco em 1928 (Carneiro Leão); Minas Gerais em 1927 (Francisco Campos); na Bahia em 1928 (Anísio Teixeira) e no Paraná (1927 Lysímaco da Costa). Tais reformas, de modo geral, tinham por objetivo modificar a área educacional no Brasil, sendo precursoras do Manifesto dos Pioneiros da Educação Nova. (IVASHITA e VIEIRA: s.d., 5).

Recebido: $\quad$ março-16 Aprovado: setembro-16 